\title{
Entre las tomas y actuales apropiaciones "ilegales" del suelo urbano
}

\author{
Yanina Inostroza ${ }^{1}$ y Pablo Schulze ${ }^{2}$
}

\author{
Fecha de recepción: 30 de octubre de 2014
}

Fecha de aprobación: 15 de diciembre de 2014

\begin{abstract}
Resumen
Las actuales apropiaciones de suelo urbano que emergen en las ciudades chilenas, conocidas comúnmente como tomas, son manifestación de una ciudad que continúa reproduciendo, desde la polarización y el conflicto, ciertas prácticas que, si bien están ancladas en patrones culturales, han sido histórica y sistemáticamente deslegitimadas y criminalizadas por el Estado como apropiaciones delictuales de la propiedad privada.

Sin embargo, en la ciudad de Coquimbo las tomas y las apropiaciones de territorios urbanos dispuestos para la vivienda se transforman en prácticas culturales que escinden por completo la lógica actual del Estado capitalista, al no responder a los caminos formales del acceso a la vivienda a través del mercado inmobiliario. El siguiente artículo permite exponer las tomas de suelos urbanos como reflejo de una manera de acceder a la vivienda que, siempre perseguida por el Estado, continúa estando presente en la mayoría de las ciudades chilenas, siendo Coquimbo y su cultura de tomas, nuestro caso a estudiar.
\end{abstract}

Palabras clave: tomas urbanas, apropiación, Estado capitalista, marginalidad urbana, cultura de tomas.

\section{Between occupations and current misappropriations of urban land}

\begin{abstract}
The current misappropriation of urban land, commonly known as occupations, emerging in Chilean cities are manifestations of a city that continues repeating, from polarization and conflict, certain practices that are well anchored in cultural patterns but have been historically and systematically delegitimized and criminalized by the State as private property illegal appropriations.
\end{abstract}

\footnotetext{
${ }^{1}$ Licenciada en Sociología, Universidad Central, Santiago de Chile. Yani.inostroza@ gmail.com

${ }^{2}$ Licenciado en Sociología, Universidad Central, Santiago de Chile. pablo.schulze.a@ gmail.com
} 
However, in Coquimbo city, occupations and misappropriations of urban lands destined to housing are transformed into cultural practices that split completely the current logic of the capitalist State, by not responding to formal ways of access to housing through the property market. The following article exposes urban land occupations as a way of accessing housing that have always been persecuted by the State, although still present in most Chilean cities. Coquimbo and its culture is our case to study.

Keywords: Urban occupations, ownership, capitalist State, urban marginality, occupation culture.

\title{
Entre a posse deassentamentos e as atuais apropriaçoes "ilegais" de terrenos urbanos
}

\begin{abstract}
Resumo
As atuais apropriações da terra urbana que emergem nas cidades chilenas, usualmente conhecidas como assentamentos, são manifestações de uma cidade que continua reproduzindo, a partir da polarização e o conflito, certas práticas que, ancoradas em padrões culturais, têm sido histórica e sistematicamente deslegitimados e criminalizados pelo Estado como apropriação delitiva da propriedade privada.

No entanto, na cidade de Coquimbo, os assentamentos e as apropriações de territórios urbanos dispostos para a moradia, transformam-se em práticas culturais que dividem completamente a lógica atual do Estado capitalista, ao não responder aos caminhos formais do acesso à habitação através do mercado imobiliário. O seguinte artigo permite expor sobre a posse de assentamentos de terras urbanas, reflexo de uma forma de acesso à habitação, que sempre perseguida pelo Estado, continua estando presente na maioria das cidades chilenas, sendo Coquimbo e sua cultura deassentamento, nosso caso para estudar.
\end{abstract}

Palavras-chave: Assentamentos urbanos, apropriação, estado capitalista, marginalidade urbana, cultura de assentamentos urbanos.

\section{Apropiación del suelo urbano como sinónimo de ilegalidad}

Al hablar de apropiación de terrenos urbanos, consideramos cualquier ocupación de una porción de ciudad donde se inscriba un sentido político, implicando la organización de personas hacia una acción en particular. En palabras de Giaretto (2013), la "toma":

Recupera este sentido existencial de la apropiación del suelo urbano, pero remarca en el sentido político de la organización de los sujetos en un colectivo (...), porque 
pone a trasluz la puja de significados y de usos que se dan sobre la tierra: para unos, como medio de producción y reproducción de la vida misma; para otros, como medio de especulación inmobiliaria y financiera. (pp. 76-77).

Dado el carácter imprescindible del suelo para la existencia, partimos con que toda persona porta su capacidad de habitar un determinado lugar; esto quiere decir, no sólo "alojarse en" ni tener algo de su propiedad, sino que apropiarse de su espacio para inscribirle su propio sentido. Un acto de lucha por la subsistencia, portando un indeleble capital político de reivindicación social.

Sin embargo, las apropiaciones de suelos urbanos, según Domínguez (2011), desde la política de erradicación que ha adoptado históricamente la institucionalidad estatal chilena, son vistas como actos que violan el derecho de propiedad privada y, por ende, deben ser eficazmente intervenidos, y las personas en cuestión expulsadas a la periferia.

Entendiendo que las operaciones urbanas son manifestación de diferentes niveles contradictorios y antagónicos de desarrollo económico, como lo vemos con las tomas, la ciudad globalizada es el lugar en el que se aprecia mejor lo problemático de la nueva economía global (Giddens, 2006). La diferenciación espacial que produce el proyecto urbano del capitalismo moderno es llevado a cabo desde la polarización extrema, producto de una revalorización-desvalorización simultánea del suelo urbano. Mientras los centros financieros reciben grandes cantidades de inversión inmobiliaria, las áreas marginadas se devalúan cada vez más. Es decir, existen espacios más rentables para el mercado y, al mismo tiempo, lugares excluidos, sin "potencial económico" alguno.

Esta segregación espacial y social de la ciudad capitalista contribuyó a que el modelo urbano moderno produjera una extrema polarización y aumentara la brecha entre ricos y pobres, confinando y excluyendo la pobreza a la periferia, donde cada fragmento pareciera vivir y funcionar de modo autónomo. Sin embargo, la segregación y segmentación espacial, como dos ca- 
ras de una misma moneda, explican la solución que, según Harvey (2004), encontró el capitalismo del siglo XX para resolver temporalmente sus contradicciones y mitigar la lucha de clases, configurando temporalmente un nuevo orden social y espacial productivamente eficiente. Esto quiere decir, el problema estructural de las apropiaciones de suelos urbanos coexistiendo con un mayor desarrollo económico de las ciudades.

Por otra parte, desde investigaciones llevadas a cabo en los guetos norteamericanos y la periferia urbana francesa, Wacquant (2007) se pregunta si existiría una convergencia epocal de regímenes de pobreza urbana, producida por políticas públicas elaboradas desde el mismo prisma neoliberal. Dos formaciones socioespaciales diferentes, pero producidas por dos lógicas institucionales de segregación que se asemejan cada vez más.

Por esto, la conceptualidad en torno a la apropiación de terrenos urbanos es un signo que deja entrever la criminalización e ilegalidad en que sumergen las políticas públicas al mundo de la pobreza, y constituye un punto de partida en la conformación de regímenes de pobreza urbana, elaborados bajo el prisma actual del neoliberalismo.

Mientras que algunos conceptos, como "asentamientos" o "tomas", remarcan el sentido de primera necesidad de la apropiación del suelo, otros conceptos, como "usurpaciones" o "invasiones", manifiestan el carácter punitivo que ha estado asociado desde siempre con las apropiaciones de suelos urbanos.

El Estado, junto a la política de erradicación, incrementa su actuación penal y gestiona la pobreza en la criminalidad -y las tomas son manifestación de aquello-, ensamblando así las políticas dirigidas a los pobres, en una mezcla de política penal y social (González Sánchez, en RES, 2011).

Por el lado de las apropiaciones urbanas de una pobreza incipiente a la que situar al margen, se constituye históricamente en las personas que migraban del campo a la ciudad, no por motivos laborales, sino simplemente por vivir en la ciudad, sin importar 
cómo ni qué medios emplearan, como si habitar en la urbanidad fuera un fin en sí mismo. Un nuevo mundo, ya no campesino ni fabril, que, clamando integración, se constituía en la apropiación "ilegal" y "delictiva".

En el caso de los orígenes chilenos de aquellos asentamientos que, como "callampas", "proliferaban" cada vez con mayor velocidad, se conforman no sólo como las primeras manifestaciones de organización social en materia de vivienda, a la espera de una respuesta legal por parte del Estado, sino que, además, como una forma de enfrentar y acceder a la propiedad privada, marcando una diferencia con el resto de las clases sociales al irrumpir en las ciudades.

Cabe recordar que, según Ducci (1993), la única toma exitosa producida gracias a una organización política de respaldo, ocurre el 22 de septiembre de 1983, cuando 8.000 familias (32.000 personas aproximadamente) constituyen los campamentos Cardenal José María Caro y Monseñor Juan Francisco Fresno, realizando así la toma más grande de la historia del país. Sin embargo, con la eliminación de los partidos políticos durante la dictadura militar chilena, todo intento de "toma de terreno" fue perseguido y reprimido con base en la política habitacional del régimen, que en 1985 se propone "erradicar" la pobreza a través de la denominada "marginalidad habitacional", como llamaría el catastro aplicado el mismo año por el Estado a estos grupos excluidos desde sus símbolos y rituales más cotidianos.

Esta marginalidad habitacional, que se acrecentaba gracias a una visión estatal de la pobreza, se transforma en el motor ideológico, junto al poco valor del suelo urbano en las periferias de la ciudad. Dicha política continúa reproduciendo lo que el crecimiento centrífugo como tendencia histórica de las ciudades latinoamericanas venía consiguiendo, es decir, continuar expulsando a la pobreza a que habite en las afueras de las ciudades, pero ahora en conjuntos habitacionales construidos por empresas inmobiliarias patrocinadas por las políticas de libre mercado. Estos 
conjuntos, localizados distantes de la ciudad establecida, se conforman desprovistos de los servicios y equipamientos mínimos, como salud, educación y trabajo, lo que potencia la exclusión social de personas y familias beneficiarias de aquellas soluciones de vivienda (Hidalgo, 2007).

\section{El Estado como gestor inmobiliario y el camino neoliberal a la vivienda}

La promoción del neoliberalismo durante los años posteriores al golpe militar, junto a una mayor disponibilidad de suelo, no terminaría provocando una disminución de su valor en las ciudades chilenas, sino que, por el contrario, un aumento, debido a los procesos especulativos que ello generó en los territorios liberados por el mercado (Sabatini, 2000).

En los años 90, la edificación masiva de viviendas sociales permitió a la política chilena situarse como exitosa, ya que disminuyó el déficit habitacional. Sin embargo, aquella solución evidenció no tan solo problemas en la construcción precaria de las casas -las conocidas casas "chubi"-, sino que desde el Estado se generó, en torno a una política de planificación territorial de la vivienda social y la ciudad, una política de segregación de la pobreza.

De los aproximadamente 700 conjuntos edificados entre 1978 y 2002, un 36\% corresponde a poblaciones con más 300 unidades. Lo anterior traduce las estrategias utilizadas por los agentes urbanos involucrados en este proceso y que dicen relación con la obtención de mayores rendimientos económicos por unidad construida y el acceso a terrenos de mayor superficie con un menor costo por metro cuadrado, que solo es ofertado en las comunas mencionadas. (p. 68).

Como consecuencia de lo anterior, Sabatini, Cáceres y Cerda (2001, citados en Brain y cols., 2010) indican que la homogeneidad social de los conglomerados residenciales de vivienda social 
se ha vuelto maligna, ya que favorece el desempleo y el crimen, entre muchos otros problemas sociales (p. 116). La masiva construcción de viviendas sociales en la periferia provocó para sus habitantes la pérdida de empleo, aumento de costos en transporte, dificultades en el acceso a la educación y la salud, y nuevas dimensiones de violencia e inseguridad.

Luego de la instalación del modelo neoliberal en Chile, cada gobierno de turno ha emitido un Decreto Supremo para la gestión de subsidios habitacionales para familias populares, los cuales han sido el principal instrumento para resolver el llamado "déficit habitacional". Actualmente, por medio del Decreto Supremo $\mathrm{N}^{\circ} 49$, las familias tienen dos opciones para acceder a una vivienda social: la postulación individual (que aún no ha tenido llamados) y la postulación colectiva, principal opción para las familias de campamentos, agrupadas bajo la figura jurídica de "Comité de vivienda" (Servicio de Vivienda y Urbanismo, 2013).

Absorbido por el mercado, el subsidio favorece el desarrollo de conglomerados de viviendas sociales en la periferia homogénea socialmente y carente de servicios. Según Brain y cols. (2010), el subsidio habitacional ha sido un subsidio a la oferta más que a la demanda (p. 117), ya que debilita la soberanía del consumidor al limitar su posibilidad de elección. Con esto, la ausencia de instrumentos y políticas públicas en torno al desarrollo urbano ha favorecido la política de la no política y con esto la segregación urbana.

Los recursos del Estado están beneficiando a los hogares de menores ingresos y estos, según Rojas (2000, citado en Artidi, 2003), confían en la política habitacional. Sin embargo, esta política aún enfrenta importantes dificultades, entre las cuales destacan: 1) la falta de coordinación entre las políticas habitacionales urbanas y la transformación del Estado en gestor inmobiliario; 2) la expansión urbana horizontal, a consecuencia de la construcción periférica de viviendas sociales; 3) la discriminación de la vivienda usada como consecuencia del sesgo hacia la vivienda 
nueva, y 4) la desigualdad en el desarrollo de la actividad inmobiliaria a lo largo del país y la homogeneización en el diseño y planes de pago que no consideran las diferentes características de las familias.

Al tomar en cuenta conglomerados urbanos homogéneos, en los que se acumula y reproduce la pobreza, el Ministerio de Vivienda y Urbanismo (MINVU) y las secretarías regionales ministeriales (SEREMI) implementan normas generales de participación ciudadana. Para la Región de Coquimbo, ambos organismos estipulan, en sus artículos $3^{\circ}$ y $4^{\circ}$, recoger la opinión de distintos actores destinatarios de las políticas y/o programas ministeriales, así como mejorar los procedimientos para acceder a los servicios y beneficios aprobados por los planes y programas del MINVU. El artículo $9^{\circ}$, por su lado, se refiere a los consejos de la sociedad civil, con representantes de organizaciones sin fines de lucro relacionadas con políticas y programas que articulan los organismos del Estado.

Sin embargo, en la realidad, ningún canal de participación funciona al momento de necesitar un lugar o un terreno para la vivienda, y ningún mecanismo municipal ni de gobierno cubre todas las necesidades básicas para muchas familias que deciden tomarse un terreno y construir ahí su casa, saltando muchas veces, obviando otras, los caminos formales que impone el Estado para acceder a la vivienda mediante sus organismos públicos. $\mathrm{Al}$ no incluir a todos los ciudadanos, sino que excluirlos por su capacidad de pago y endeudamiento, la participación entonces sale del camino institucional basado en la postulación al subsidio habitacional, y se da en los contextos de tomas y apropiaciones, en los que la marginalidad urbana se deja de lado, dando paso a organización y participación social, fuera de los mecanismos dominantes.

Actualmente, en Chile existen 657 campamentos, según el Catastro de Campamentos 2011, los cuales agrupan a 83.862 personas a lo largo del país. Dicho fenómeno es histórico y ha tenido 
diferentes denominaciones en el pasado: rancheríos, conventillos, poblaciones "callampa", entre otros (Salazar y Pinto, 2002).

\section{Coquimbo y su historia con las apropiaciones de terrenos urbanos}

Para la historia de Coquimbo, el poblamiento masivo de los cerros que bordean la bahía de la ciudad ha sido mediante ocupaciones y urbanizaciones, sin una planificación ni orden estatal previo. El sector poniente de la ciudad, conocido como la "Parte Alta", ha sido testigo de las sucesivas tomas y apropiaciones urbanas, que han modificado el límite y reconfigurado el borde costero coquimbano, siendo uno de los pocos lugares aún no urbanizados por completo que van quedando en la región, constituyéndose además como una importante reserva ambiental y paisajística (Cartografía sociocultural de los barrios populares de Coquimbo, 2010).

Como nos muestra el transcurso de la historia de Coquimbo hasta la actualidad, la toma de terreno, si bien no es legitimada institucionalmente como estrategia de urbanización, sí es validada culturalmente por los habitantes de Coquimbo, en la medida en que esta estrategia se reproduce durante la historia de la comuna. De esta manera, la toma de terrenos no solo significa acceder a una porción de suelo, sino que se ancla a partir de procesos identitarios que llevan a una cantidad de familias, en muchos casos de generación en generación, a tomarse un terreno y no otro.

Que no sea legitimada institucionalmente queda en evidencia con las erradicaciones a finales del año 2013, que han sido llevadas a cabo por las autoridad municipales y policiales, como el caso de la toma "La Gruta", en el sector Faro Punta de Tortuga en la Parte Alta de Coquimbo (Equipo El Observatodo, 2013). Numerosas familias fueron desalojadas de los lugares en los que, en otros años, se han instalado grupos familiares por completo, lo que produjo un choque inevitable entre el Estado y la sociedad 
civil; tensión entre la política pública de vivienda y urbanismo versus una cultura de tomas en Coquimbo, que hasta hoy sigue presente como manera de acceder y solucionar los problemas de habitabilidad.

Ya que los terrenos se hacen cada vez más escasos en el sector, donde gran parte del paño urbano ha sido dispuesto para conjuntos habitacionales construidos por empresas privadas, la tensión no se manifiesta tan solo en la necesidad de vivienda, sino en el acceder a la ciudad, y a lo que significa vivir en la Parte Alta de Coquimbo.

Los reclamos también perfilan lo anterior. Es decir, las personas manifiestan su interés por quedarse en estos lugares, rechazando la posibilidad de vivir en la periferia. Esto se explicaría, según Brian et al. (2010), porque la existencia de campamentos no es solo la manifestación del déficit habitacional, sino que las familias de campamento, además de querer dejar de vivir como allegados, "tienen una preferencia clara por mantenerse en el lugar en que está emplazado su campamento o en las cercanías" (p. 115), ya que vivir en campamento evita la segregación hacia la periferia y favorece la localización en la ciudad, no solo para el acceso a servicios sino también a la experiencia de heterogeneidad, el encuentro con otras clases sociales y, así, el acceso a oportunidades. El campamento se aleja entonces de la experiencia del gueto, como señalan los mismos pobladores "aquí [en el campamento] ${ }^{3}$ estamos mejor en el sentido que los niños se están criando de otra manera" (Dirigente de campamento RM, citado por Claro, 2011).

Las personas que viven en las tomas de Coquimbo se refieren de manera clara a las diferencias entre las tomas y los campamentos. Para los habitantes del lugar donde se emplazan las tomas en Coquimbo, la toma, como acto anclado en la cultura y la identidad de los coquimbanos, difiere de la visión clásica de

\footnotetext{
${ }^{3}$ Texto entre corchetes agregado para referencia.
} 
la pobreza, la que ve en los campamentos momentos previos y de presión por necesidades habitacionales. Es decir, la toma en la Parte Alta de Coquimbo se diferencia a sí misma del clásico campamento, momentáneo y no duradero, como lo pretende demostrar la toma, junto a sus habitantes y sus redes familiares. La toma se vuelve así en una decisión que, como vemos, trasciende el tiempo y alcanza las redes familiares, identitarias y de pertenencia al lugar.

\section{A modo de conclusión}

Si, por un lado, el acceso a la vivienda y a la ciudad están dominados por completo por el mercado inmobiliario, el cual se apoya en la gestión que realiza el Estado del suelo urbano, las tomas se conforman como prácticas culturales de habitabilidad y acceso a la vivienda, que escinden por completo la lógica del Estado capitalista y neoliberal, el cual gestiona lo urbano y resguarda la propiedad privada.

Por otro lado, el actuar del Estado capitalista gira siempre en torno al discurso de la ilegalidad y la criminalidad. Nunca el Estado chileno ha considerado la apropiación de suelo urbano como una forma legítima de habitabilidad, sino que, por el contrario, las políticas públicas han girado y lo siguen haciendo en torno a la erradicación. Como se menciona en las actuales tomas de Coquimbo, expresión cultural anclada en los habitantes que, con el tiempo, se diluye cada vez más frente a un Estado penal que castiga y reprime las tomas, olvidando la dimensión cultural y social que allí subyace.

La ciudad se vuelve así un escenario de dominación y lucha de clases, obligándonos a reinterpretar la urbanidad fuera de toda ciencia denominada "dura" y situarla en lugares de dominación y resistencia, producto de una serie de paradojas y contradicciones que se instalarían en instancias de apropiación y (re) producción del espacio urbano, en el cual el caso de las actuales tomas muestra cómo conviven patrones culturales que continúan 
siendo deslegitimados, perseguidos y erradicados por las políticas públicas.

Para el caso en mención, podemos ver una ciudad a la que se le promete el desarrollo como consecuencia de la ampliación del puerto, gracias al corredor bioceánico que se espera realizar en los próximos años, como el lugar del conflicto por el suelo urbano y por el acceso a la vivienda (Equipo El Observatodo, 2011). Con un mayor desarrollo de la ciudad y de la región, se espera que el conflicto por el suelo urbano entre la sociedad civil y el Estado, como gestor de la ciudad, y su acceso y propiedad, continúe tomando otras características.

La mayor dificultad que enfrenta la política pública frente al fenómeno de las tomas y los campamentos es el carácter estructural de estos, en la medida en que continúan emergiendo en ciudades más globalizadas y neoliberales. Sin embargo, este potencial es lo que debemos recuperar de las prácticas políticas de los sujetos sociales en cuestión, sin aislarlas de su relación de mutuo condicionamiento con los mecanismos que el Estado despliega, no solo para diluir o neutralizar el conflicto actual, sino, además, para corroer las bases y proyecciones de ese poder político. En otras palabras, junto al cada vez mayor desgaste de la capacidad organizativa de las actuales tomas se encuentra el gran potencial de organización social en las tomas que se vislumbra en el caso de Coquimbo, que ha sabido subsistir como una estrategia de habitabilidad, que escinde por completo la lógica del Estado capitalista y del actual neoliberalismo como modelo político y social que adopta Chile en la actualidad.

\section{Referencias}

Arditi, C.; Carrasco, G.; Jirón, P. y Sepúlveda, R. (2003). Gestión de suelo urbano y vivienda social. Elementos para una discusión. Santiago de Chile: Instituto de la Vivienda, Universidad de Chile.

Brain Valenzuela, I.; Prieto Suárez, José Joaquín y Sabatini Downey, Francisco (2010). Vivir en Campamentos: ¿Camino ha- 
cia la vivienda formal o estrategia de localización para enfrentar la vulnerabilidad? EURE (Santiago), 36(109), 111-141. Recuperado en 12 de marzo de 2015, de http:/ / www.scielo.cl/scielo.php?script=sci_arttext\&pid=S0250$71612010000300005 \& \operatorname{lng}=$ es\&tlng=es.10.4067 / S025071612010000300005 .

Domínguez, P. (2011). Campamentos, viviendas y acceso a la ciudad para los pobres. Revista CIS, 14, 73-94.

Claro, M. (2012). Catastro 2011: Mapa Social de Campamentos. Santiago de Chile: Secretaría Ejecutiva de Campamentos, Ministerio de Vivienda y Urbanismo.

Ducci, Ma E. (1997). Chile: El lado obscuro de una política de vivienda exitosa. Revista electrónica Eure, XXIII(69), 99-115.

Harvey, D. (2004). El nuevo imperialismo: acumulación por desposesión. En Leo Panitch y Colin Leys (eds.). Socialists register. London: Merlin Press.

Hidalgo, R. (2007). ¿Se acabó el suelo en la gran ciudad? Las nuevas periferias metropolitanas de la vivienda social en Santiago de Chile. Revista electrónica Eure, 33(98), 57-75.

Giaretto, M. (2011). Un análisis crítico de las relaciones entre Estado capitalista y toma de tierras urbanas. Argentina: Publi Fadecs.

Giddens, A. (2007). Sociología. Madrid: Alianza.

Sabatini, F. (2000). Reforma de los mercados de suelo en Santiago. Chile: efectos sobre los precios de la tierra y la segregación residencial. Revista electrónica Eure, 77, 49-80.

Salazar, G. y Pinto, J. (2002). Historia Contemporánea de Chile IV. Hombría y Feminidad. Santiago de Chile: LOM.

Servicio de Vivienda y Urbanismo (2013). Servicio de Vivienda y Urbanismo Región de Coquimbo. Recuperado el noviembre de 2013, de www.serviu4.cl

González Sánchez, I. (2011). Castigar a los pobres: el gobierno neoliberal de la inseguridad ciudadana. Versión Online. Revista Española de Sociología (RES) $\mathrm{n}^{\circ} 15$.

Wacquant, L. (2007). Los condenados de la ciudad. Guetos, periferias y Estado. Argentina: Siglo XXI Editores. 
